\title{
Predicting Stock Market Movements with a Time-Varying Consumption-Aggregate Wealth Ratio $\#$
}

Tsangyao Chang ${ }^{*}$, Rangan Gupta** ${ }^{* *}$ Anandamayee Majumdar ${ }^{* * *}$ and Christian Pierdzioch ${ }^{* * * * *}$

\begin{abstract}
We develop a time-varying measure of cay $\left(c a y^{T V P}\right)$ using time-varying cointegration, and then compare the predictive ability of cay ${ }^{T V P}$ with cay and a Markov-switching cay $\left(\right.$ cay ${ }^{M S}$ ) for excess stock returns and volatility in the US over the period 1952:Q2-2015:Q3, using a $k$ th order nonparametric causality-in-quantiles test. We find that time-varying cointegration exists between consumption, asset wealth, and labor income. In addition, while there is no evidence of predictability of volatility of excess returns from $c a y, c a y^{M S}$, or $c a y^{T V P}$, they tend to act as strong predictors of stock returns, with $c a y^{T V P}$ being important during the bearish phases of the equity market.
\end{abstract}

Keywords: Consumption-aggregate wealth ratio; Time-varying cointegration; Stock returns; Volatility; Nonparametric causality-in-quantiles test.

JEL Codes: C22, G10.

\footnotetext{
\# We would like to thank two anonymous referees for many helpful comments. The usual disclaimer applies.

* Department of Finance, Feng Chia University, Taichung, Taiwan, E-mail address: tychang@ mail.fcu.edu.tw.

** Corresponding author. Department of Economics, University of Pretoria, Pretoria, 0002, South Africa; E-mail address: rangan.gupta@up.ac.za.

*** Center for Advanced Statistics and Econometrics, Soochow University, Suzhou, China; Email address: anandamayee.majumdar@gmail.com.

***** Department of Economics, Helmut Schmidt University, Holstenhofweg 85, P.O.B. 700822, 22008 Hamburg, Germany; Email address: c.pierdzioch@ @su-hh.de.
} 


\section{Introduction}

Lettau and Ludvigson (2001), using a wide class of optimal models of consumer behaviour showed in an influenctial paper that the consumption-aggregate wealth (human capital plus asset holdings) ratio (cay) summarizes expected returns on aggregate wealth or the market portfolio and, hence, is a strong predictor of US quarterly stock returns. Ever since, a large number of studies have confirmed this finding for other developed and emerging countries (see for example, Sousa, 2010, 2015; Afonso and Sousa, 2011; Rapach and Zhou, 2013; Rocha Armada et al. 2015; Caporale and Sousa, 2016). Moreover, Ludvigson and Ng (2007), show that cay can also predict volatility of US excess returns. More recently, Bianchi et al. (2016) provide evidence of infrequent shifts, or breaks, in the mean of cay. As a result, the authors introduce a Markov-switching version of the consumption-wealth ratio, i.e., cay ${ }^{M S}$, and show that, relative to the classic cay, the regime-switching version has superior predictive power for quarterly excess stock market returns.

At this stage it must be pointed out that, as is standard practice in the literature on stock returns predictability, the above-mentioned studies rely on linear predictive regression frameworks when predicting stock returns and volatility based on the consumption-aggregate wealth ratios. But, as has recently been shown by Bekiros and Gupta (2015) and Balcilar et al. (2017a), the relationship between stock-market movements and cay or cay ${ }^{M S}$ is in fact nonlinear, and hence, the linear models used in the literature are misspecified and results derived from them cannot be relied upon. Interestingly, Bekiros and Gupta (2015) investigate the predictability of US stock returns and its volatility emanating from cay and $\operatorname{cay}^{M S}$ using the $k$-th order conditional mean-based nonparametric causality test of Nishiyama et al. (2011), and find no evidence of predictability. However, more recently, Balcilar et al. (2017a) using a quantiles-based extension of the above test as developed by Balcilar et al. (2016a), show that while stock-market volatility is still unpredictable, cay and cay ${ }^{M S}$ can predict the equity premium. However, cay ${ }^{M S}$ performs better than cay only at certain quantiles (in general the moderately-lower ones below the median), and not over the entire conditional distribution.

We first contribute to the literature on the instability of the consumption function, as indicated by Bianchi et al. (2016), by estimating a time-varying cointegration equation capturing the relationship between consumption, wealth, and income. In this regard, we use the (single-equation) smooth time-varying cointegration (STVC) model of Park and Hahn (1999), as an extension of the single-equation cointegration approaches that Lettau and 
Ludvigson (2001) and Bianchi et al. (2016) use to obtain estimates of the consumptionaggregate wealth ratio. The STVC framework renders it possible to test whether cointegration exists and, if so, whether the long-run relationship is in fact time varying. Using this framework, we are able to recover the evolution of the wealth and income elasticities, through time-varying parameters. Hence, we can capture any instability in the consumption function (if it exists) appropriately. Once we have estimated the STVC model, we recover the residuals of the model and derive a new measure of the consumption-aggregate wealth ratio, which we call $c a y^{T V P}$. Then, as part of our second objective, as is standard practice in the literature, we use $c a y^{T V P}$ to predict the US equity premium over the quarterly period from 1952:Q2 to 2015:Q3, and compare its performance with the classical cay and its Markovswitching version, $c a y^{M S}$. Given the evidence of nonlinearity in the relationship between consumption-aggregate wealth ratios and excess stock returns as shown by Bekiros and Gupta (2015), and following Balcilar et al. (2017a), we conduct the predictability analysis based on the $k$-th order nonparametric causality-in-quantiles test that has been recently developed by Balcilar et al. (2016a).

The test of Balcilar et al. (2016a) studies higher order causality over the entire conditional distribution of the dependent variable and is inherently based on a nonlinear dependence structure between the variables, as captured by data-driven nonparametric functions. It essentially combines the causality-in-quantiles test of Jeong et al. (2012) and the highermoment nonparametric causality test of Nishiyama et al. (2011). ${ }^{1}$ To the best of our knowledge, this is the first paper that develops a measure of consumption-aggregate wealth ratio from a time-varying cointegration model, and then uses this measure to evaluate its predictive power of the equity premium and its volatility, relative to cay and $c a y^{M S}$, based on a nonparametric causality-in-quantiles framework.

The rest of this research is organized as follows: Section 2 describes the econometric frameworks of time-varying cointegration and higher-moment nonparametric causality-inquantiles test. Section 3 presents the data and discusses the empirical results. Finally, Section 4 concludes.

\footnotetext{
${ }^{1}$ As indicated by Balcilar et al. (2016a), the causality-in-quantile approach has the following novelties: Firstly, it is robust to misspecification errors as it detects the underlying dependence structure between the examined time series. Secondly, via this methodology, it makes it possible to test for not only causality-in-mean ( $1^{\text {st }}$ moment), but also causality that may exist in the tails of the distribution of the variables. Finally, it renders it possible also to investigate causality-in-variance and, thus, study higher-order dependency.
} 


\section{Econometric Methodologies}

\subsection{Time Varying Cointegration Test}

According to Park and Hahn (1999), the STVC model can be specified as follows:

$$
c_{q j}=\beta_{0}+\alpha_{q}+\beta_{q j}^{\prime} X_{q j}+\varepsilon_{q j}=\beta_{0}+\alpha_{q}+\beta_{1(q j)} a_{q j}+\beta_{2(q j)} y_{q j}+\varepsilon_{q j},
$$

where, subscripts $q$ and $j$ indicate the quarter $q(=1,2,3)$ of year $j(=1,2,3, \ldots, T) ; c_{q j}$ is the natural logarithm of real consumption; $X_{q j}=\left(a_{q j}, y_{q j}\right)^{\prime}$ represents a vector of explanatory variables, i.e., natural logarithms of real asset wealth $(a)$ and real labor income $(y) ; \alpha_{q}$ denotes the fixed quarterly effect to capture seasonality present in the consumption function; $\beta_{0}$ denotes the constant term, and $\varepsilon_{q j}$ denotes the error term. $\beta_{q j}=\left(\beta_{1(q j)}, \beta_{2(q j)}\right)^{\prime}$ is a vector of time-varying parameters corresponding to $X_{q j}=\left(a_{q j}, y_{q j}\right)^{\prime}$. Specifically, $\beta_{q j}=\beta(t / n)$ is a smooth function defined on the inteval [0,1], where $n$ is the number of observations, and $t$ is the order of observation in the total sample given by $t=4(j-1)+q$. Using the flexible Fourier function to approximate the time-varying parameter, $\beta_{q j}$, Eq. (1) can be rewritten as:

$$
c_{q j}=\beta_{0}+\alpha_{q}+\gamma_{k}^{\prime} X_{k q j}+\varepsilon_{k q j}
$$

where, $\varepsilon_{k m j}=\varepsilon_{m j}+\left[\beta(t / n)-\beta_{k}(t / n)\right] X_{k q j}, X_{k q j}=f_{k}(t / n) \otimes X_{q j}$, and $f_{k}=\left(1, \lambda, \varphi_{1}^{\prime}(\lambda), \ldots, \varphi_{k}^{\prime}(\lambda)\right)^{\prime}$ with $\lambda \in[0,1], \varphi_{i}(\lambda)=(\cos 2 \pi i \lambda, \sin 2 \pi i \lambda)^{\prime}, i=1,2, \ldots . .$, and $\gamma_{k}=\left(\gamma_{k, 1}^{\prime}, \gamma_{k, 2}^{\prime}, \ldots, \gamma_{k, 2(k+1)}^{\prime}\right)^{\prime} ; \otimes$ denotes the Kronecker product.

In order to obtain an efficient estimator that can generate a valid inference for the timevarying parameters, the canonical cointegrating regression (CCR, hereafter) proposed by Park (1992) is used to estimate Eq. (2). In this way, Park and Hahn (1999) show that the CCR estimator of $\beta_{k}$ is a consistent estimator of $\beta$.

There are two model-specification tests proposed by Park and Hahn (1999) for the STVC model. The first test examines the null hypothesis of STVC against the alternative hypothesis of a spurious regression with non-stationary errors. The second test investigates the null hypothesis of the fixed-coefficient cointegration model against the alternative hypothesis of the STVC model. The first test statistic is given by:

$$
\tau^{*}=\frac{R S S_{T V C}-R S S_{T V C}^{s}}{\omega_{*}^{2}},
$$


where, $R S S_{T V C}$ and $R S S_{T V C}^{s}$ represent the sum of squared residuals from the CCR estimation for Eq. (2), and the same equation augmented with $s$ additional superfluous regressors (such as time polynomial terms, $\left.t, t^{2}, t^{3}, \ldots, t^{s}\right)$, respectively, and $\omega_{*}^{2}$ is the conditional long-run variance of the residuals from the transformed regression. The limit distribution of $\tau^{*}$ is a chi-square distribution with $s$ degrees of freedom.

The second tests statistic is given by:

$$
\tau_{1}^{*}=\frac{R S S_{F C}-R S S_{F C}^{s}}{\omega_{*}^{2}}
$$

where, $R S S_{F C}$ and $R S S_{F C}^{s}$ represent the sum of squared residuals from CCR estimation for Eq. (2) obtained by restricting the parameters to be constant over time, and the same equation augmented with $s$ additional superfluous regressors, respectively. The limit distribution of $\tau_{1}^{*}$ is also a chi-square distribution with $s$ degrees of freedom.

\subsection{Nonparametric Causality-in-Quantiles Test}

Next, we briefly present the methodology for the detection of nonlinear causality via a hybrid approach developed by Balcilar et al. (2016a), which in turn is based on the frameworks of Nishiyama et al. (2011) and Jeong et al. (2012). Our description of the technical details of the test is relatively compact and heavily draws on Balcilar et al. (2016b, d; 2017b, 2017c), who have introduced this test into the empirical finance literature.

We start by denoting excess returns by $y_{t}$ and the predictor variable (in our case, cay, cay ${ }^{M S}$, or $\left.c a y^{T V P}\right)$ as $x_{t}$. We further let $Y_{t-1} \equiv\left(y_{t-1}, \ldots, y_{t-p}\right), X_{t-1} \equiv\left(x_{t-1}, \ldots, x_{t-p}\right), Z_{t}=\left(X_{t}, Y_{t}\right)$ and $F_{y_{t} \mid Z_{t-1}}\left(y_{t}, Z_{t-1}\right)$ and $F_{y_{t} \mid Y_{t-1}}\left(y_{t}, Y_{t-1}\right)$ denote the conditional distribution functions of $y_{t}$ given $Z_{t-1}$ and $Y_{t-1}$, respectively. If we let denote $Q_{\theta}\left(Z_{t-1}\right) \equiv Q_{\theta}\left(y_{t} \mid Z_{t-1}\right)$ and $Q_{\theta}\left(Y_{t-1}\right) \equiv Q_{\theta}\left(y_{t} \mid Y_{t-1}\right)$, we have $F_{y_{t} \mid Z_{t-1}}\left\{Q_{\theta}\left(Z_{t-1}\right) \mid Z_{t-1}\right\}=\theta$ with probability one. As a result, the (non)causality in the -th quantile hypotheses to be tested are:

$$
\begin{aligned}
& H_{0}: P\left\{F_{y_{t} \mid Z_{t 1}}\left\{Q\left(Y_{t 1}\right) \mid Z_{t 1}\right\}=\right\}=1, \\
& H_{1}: \quad P\left\{F_{y_{t} \mid Z_{t 1}}\left\{Q\left(Y_{t 1}\right) \mid Z_{t 1}\right\}=\right\}<1 .
\end{aligned}
$$

Jeong et al. (2012) use the distance measure $J=\left\{\varepsilon_{t} E\left(\varepsilon_{t} \mid Z_{t-1}\right) f_{z}\left(Z_{t-1}\right)\right\}$, where $\varepsilon_{t}$ is the regression error term and $f_{z}\left(Z_{t-1}\right)$ is the marginal density function of $Z_{t-1}$. The regression 
error $\varepsilon_{t}$ emerges based on the null hypothesis in (1), which can only be true if and only if $E\left[1\left\{y_{t} \leq Q_{\theta}\left(Y_{t-1}\right) \mid Z_{t-1}\right\}\right]=\theta$ or, expressed in a different way, $1\left\{y_{t} \leq Q_{\theta}\left(Y_{t-1}\right)\right\}=\theta+\varepsilon_{t}$, where $\mathbf{1}\{\rtimes$ is the indicator function. Jeong et al. (2012) show that the feasible kernel-based sample analogue of $J$ has the following format:

$$
\hat{J}_{T}=\frac{1}{T(T 1) h^{2 p}} \sum_{t=p+1}^{T} \sum_{s=p+1, s \neq t}^{T} K\left(\frac{Z_{t 1} Z_{s 1}}{h}\right) \hat{t s},
$$

where $K(\cdot)$ is the kernel function with bandwidth $h, T$ is the sample size, $p$ is the lag order, and ${ }^{\wedge}{ }_{t}$ is the estimate of the unknown regression error, which is given by

$$
\hat{t_{t}}=1\left\{y_{t} \quad Q\left(Y_{t 1}\right)\right\} .
$$

$\hat{Q}_{\theta}\left(Y_{t-1}\right)$ is an estimate of the $\theta^{\text {th }}$ conditional quantile of $y_{t}$ given $Y_{t-1}$, and we estimate $\hat{Q}_{\theta}\left(Y_{t-1}\right)$ using the nonparametric kernel method as

$$
\hat{Q}_{\theta}\left(Y_{t-1}\right)=\hat{F}_{y_{t} \mid Y_{t-1}}^{-1}\left(\theta \mid Y_{t-1}\right)
$$

where $\hat{F}_{y_{t} \mid Y_{t-1}}\left(y_{t} \mid Y_{t-1}\right)$ is the Nadarya-Watson kernel estimator given by

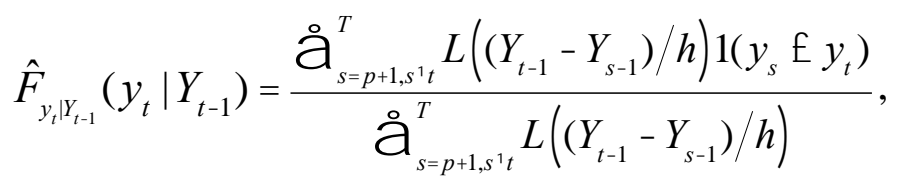

with $L(\cdot)$ denoting the kernel function and $h$ the bandwidth.

As an extension of Jeong et al. (2012)'s framework, Balcilar et al. (2016a) develop a test for the second moment. In particular, we can test the causality between $c a y, c a y^{M S}$, or $c a y^{T V P}$ and (excess) stock returns volatility. Adapting the approach in Nishiyama et al. (2011), higherorder quantile causality can be specified in terms of the following hypotheses as

$$
\begin{aligned}
& H_{0}: P\left\{F_{y_{t}^{k} \mid Z_{t 1}}\left\{Q\left(Y_{t 1}\right) \mid Z_{t 1}\right\}=\right\}=1, \quad \text { for } k=1,2, \ldots, K, \\
& H_{1}: P\left\{F_{y_{t}^{k} \mid Z_{t 1}}\left\{Q\left(Y_{t 1}\right) \mid Z_{t 1}\right\}=\right\}<1 \quad \text { for } k=1,2, \ldots, K \text {. }
\end{aligned}
$$

We can integrate the entire framework and test whether $x_{t}$ Granger causes $y_{t}$ in quantile $\theta$ up to the $k^{\text {th }}$ moment using Eq. (11) to construct the test statistic in Eq. (10) for each $k$. The causality-in-variance test can be calculated by replacing $y_{t}$ in Eqs. (7) and (8) with $y_{t}^{2}$ measuring the volatility of excess stock returns. However, one can show that it is difficult to combine the different statistics for each $k=1,2, \ldots, K$ into a single statistic for the joint null in Eq. (11), because the statistics are mutually correlated (Nishiyama et al., 2011). Balcilar et al. 
(2016a), thus, propose a sequential-testing method as described in Nishiyama et al. (2011). First, as in Balcilar et al. (2016a), we test for nonparametric Granger causality in the first moment (i.e. $k=1$ ). Nevertheless, failure to reject the null for $k=1$ does not automatically lead to no-causality in the second moment. Thus, we construct the test for $k=2$, as discussed in detail in Balcilar et al. (2016a).

The empirical implementation of causality testing via quantiles entails specifying three key parameters: the bandwidth $h$, the lag order $p$, and the kernel type for $K(\cdot)$ and $L(\cdot)$. We use a lag order (of one) based on the Schwarz information criterion (SIC), which is known to choose a parsimonious model as compared with other lag-length selection criteria. The SIC criterion helps to overcome the issue of over-parameterization that typically arises in studies using nonparametric frameworks. For each quantile, we determine the bandwidth parameter (h) by using the leave-one-out least-squares cross validation method. Finally, for $K(\cdot)$ and $L(\cdot$ ), we use Gaussian kernels.

\section{Data and Empirical Results}

Our quarterly dataset comprises excess stock returns, cay, $c a y^{M S}$, and $c a y^{T V P}$, with data on cay and $c a y^{M S}$ obtained from Professor Martin Lettau's website: http://faculty.haas.berkeley.edu/lettau/data_cay.html. In order to compute $c a y^{T V P}$, data on real values of personal consumption expenditures $(c)$, asset holdings, i.e., net hosehold worth $(a)$, and labor income (y) are also obtained individually from the above data weblink of Professor Lettau. As our plan is to compare the predictive ability of the three alternative formulations of the consumption-wealth ratio, we standardize them by dividing the actual series by the corresponding standard deviations. Our data spans over the quarterly period of 1952:Q22015:Q3, with the start and end dates being driven by data availability (of the variables under consideration) at the time of writing of this paper.

Excess stock-market returns are computed as the excess returns of a market index (exsr) over the risk-free asset return, which is common practice in the relevant literature. Specifically, we calculate the continuously compounded log returns of the Center for Research in Security Prices (CRSP) index (including dividends) minus the 3-month Treasury bill rate. We also compute the volatility of excess stock-market returns (exsv) using the squared values of exsr. ${ }^{2}$

\footnotetext{
${ }^{2}$ exsr and exsv are negatively and positively skewed respectively, with both having excess kurtosis. Both these variables have non-normal distributions, as statistically suggested by the rejection of the null hypothesis of normality under the Jarque-Bera test at the highest level of significance. This evidence of heavy tails for both
} 
Data on the value-adjusted CSRP index and the risk free rate are obtained from Professor Amit Goyal's website: http://www.hec.unil.ch/agoyal/. Note that, as pointed out by Lettau and Ludvigson (2001), the CRSP Index (which includes the NYSE, AMEX, and NASDAQ) is believed to provide a better proxy for non-human components of total asset wealth because it is a much broader measure than the S\&P 500 index.

We start off with our analysis of time-varying cointegration. ${ }^{3}$ In Table 1, we observe that not only is the fixed-coefficient cointegration model rejected in favour of the STVC model (at the $1 \%$ level of significance), but we are also unable to reject the null hypothesis of time-varying cointegration (at the conventional 5\% level of significance) against the alternative of no cointegration. In other words, the two tests of Park and Hahn (1999) not only suggest that cointegration exists, but it does so in a time-varying fashion, thus justifying the use of the STVC model to detect the long-run relationship between consumption, asset wealth, and labor income.

Table 1. Time Varying Cointegration Tests (1952Q1-2015Q3)

\begin{tabular}{lcc}
\hline Model Specification Test & $\begin{array}{c}\mathrm{H}_{0} \text { : Fixed Coefficient } \\
\text { Cointegration Model } \\
\end{array}$ & $\begin{array}{c}\mathrm{H}_{0}: \text { STVC Model } \\
\mathrm{H}_{\mathrm{A}}: \text { STVC Model }\end{array}$ \\
\cline { 2 - 3 } & $\tau_{1}^{*}$ & $\tau^{*}$ \\
\hline Test Statistic & $402.9754^{* * *}$ & 4.7763 \\
$1 \%$ Critical Value & 13.2767 & 13.2767 \\
$5 \%$ Critical Value & 9.4877 & 9.48777
\end{tabular}

Note: $* * *$ represents significance at $1 \%$ level.

exsr and exsv, in turn, provides a preliminary motivation to use the causality-in-quantiles test. Complete details of these results are available upon request from the authors.

${ }^{3}$ As is standard practice, as a pre-test requirement, we also checked for whether $c, a$ and $y$ are $\mathrm{I}(1)$ processes using the linear Augmented Dickey-Fuller (ADF, Dickey and Fuller, 1981) and Phillips-Perron (PP, Phillips and Perron, 1988) tests, and the nonlinear unit root test of Kapetanios et al., (2003, KSS). The results reported in Table A1 confirm that the variables are indeed unit-root processes, and hence satisfy the data requirement for a test of cointegration. 
Figure 1. Time-Varying Wealth and Income Elasticities

1(a): Wealth Elasticity:

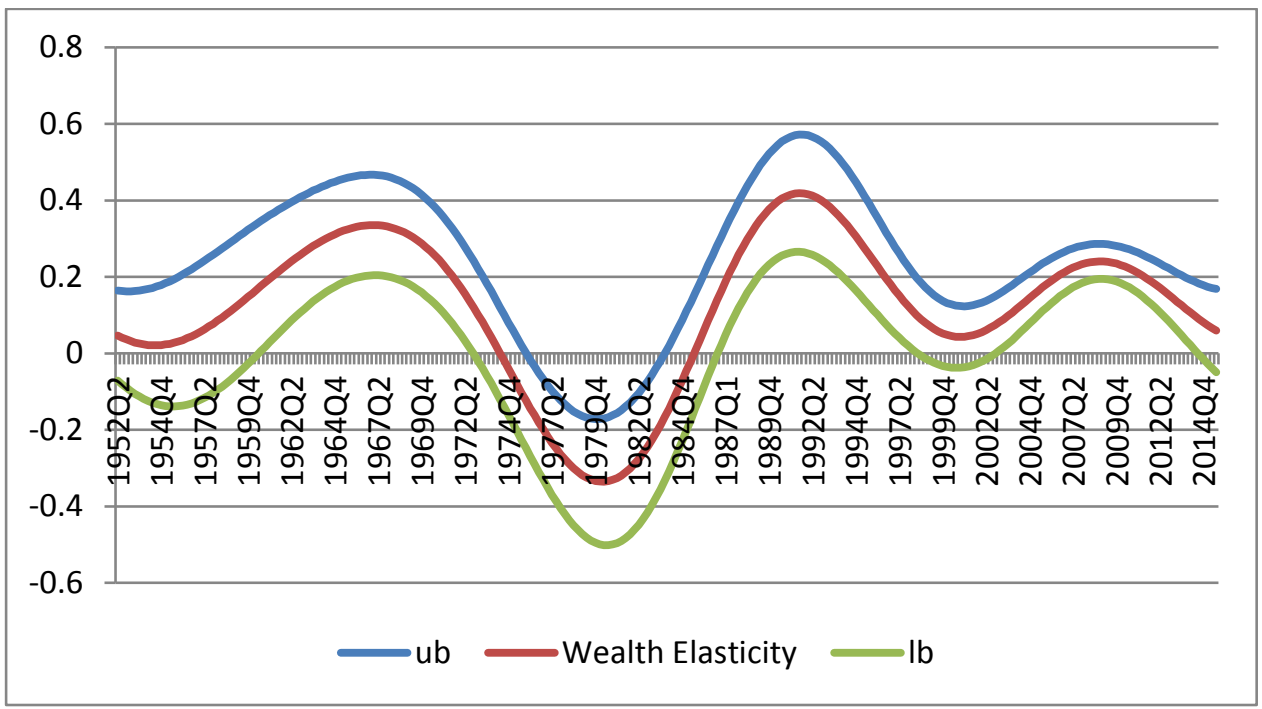

1(b): Income Elasticity:

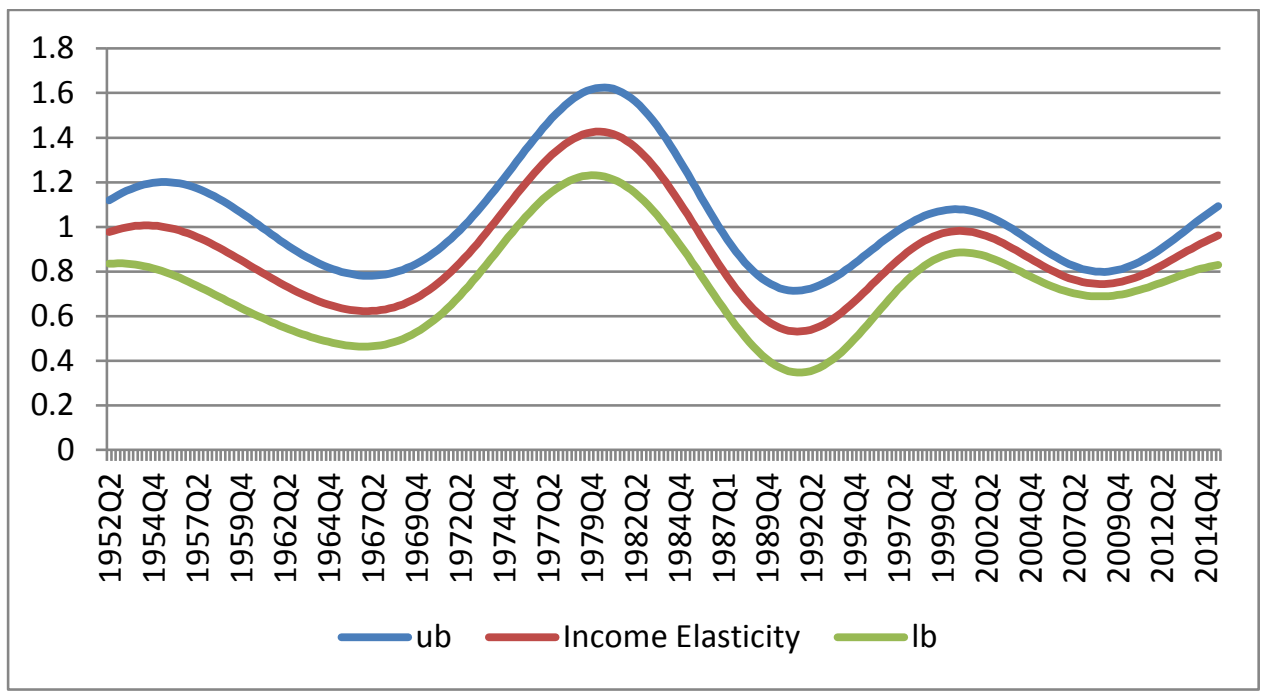

Note: $\mathrm{ub}$ and $\mathrm{lb}$ denotes the $95 \%$ upper and lower confidence bands respectively.

Given the existence of time-varying cointegration, we present in Figure 1 the paths of the time-varying elasticities of consumption with respect to wealth and income, with the elasticities being more or less mirror image of each other. The wealth and income effects evolve in a smooth fashion over time, with the parameter corresponding to labor income being consistently significant at the $5 \%$ level over the entire sample period. In general, barring some periods at the beginning and end of the sample, the wealth effect is also significant. While the income effect is always positive, the wealth effect is negative over the period from 1974:Q3 to 1985:Q2, with the negative effect being significant at the 5\% level 
starting in 1976:Q1. Note that, given the wealth-effect channel, the general underlying logic is that a rise in asset prices, especially if it is considered to be permanent, increases expected income of households and, hence, consumption, while also making it easier for firms to finance investment opportunities (Simo-Kengne et al., 2015). But, as pointed out by Ludwig and Sløk (2004), it is also possible that stakeholders draw on their wealth as positive asset returns increase their financial investment and, hence, reduce their consumption. In other words, the wealth effect can either increase or decrease consumption, with the final effect depending on the two forces discussed above.

Having estimated the STVC model, we present in Figure 2 the residuals from the timevarying cointegration equation, i.e., $c a y^{T V P}$, along with cay and $c a y^{M S} \cdot{ }^{4}$ As can be seen from the figure, the three standardized measures of the consumption-wealth ratio have a similar pattern of movement, though the $c a y^{T V P}$ in general tends to fluctuate more than the other two measures. $^{5}$

Figure 2. Plots of standardized cay, $c a y^{M S}$ and $c a y^{T V P}$

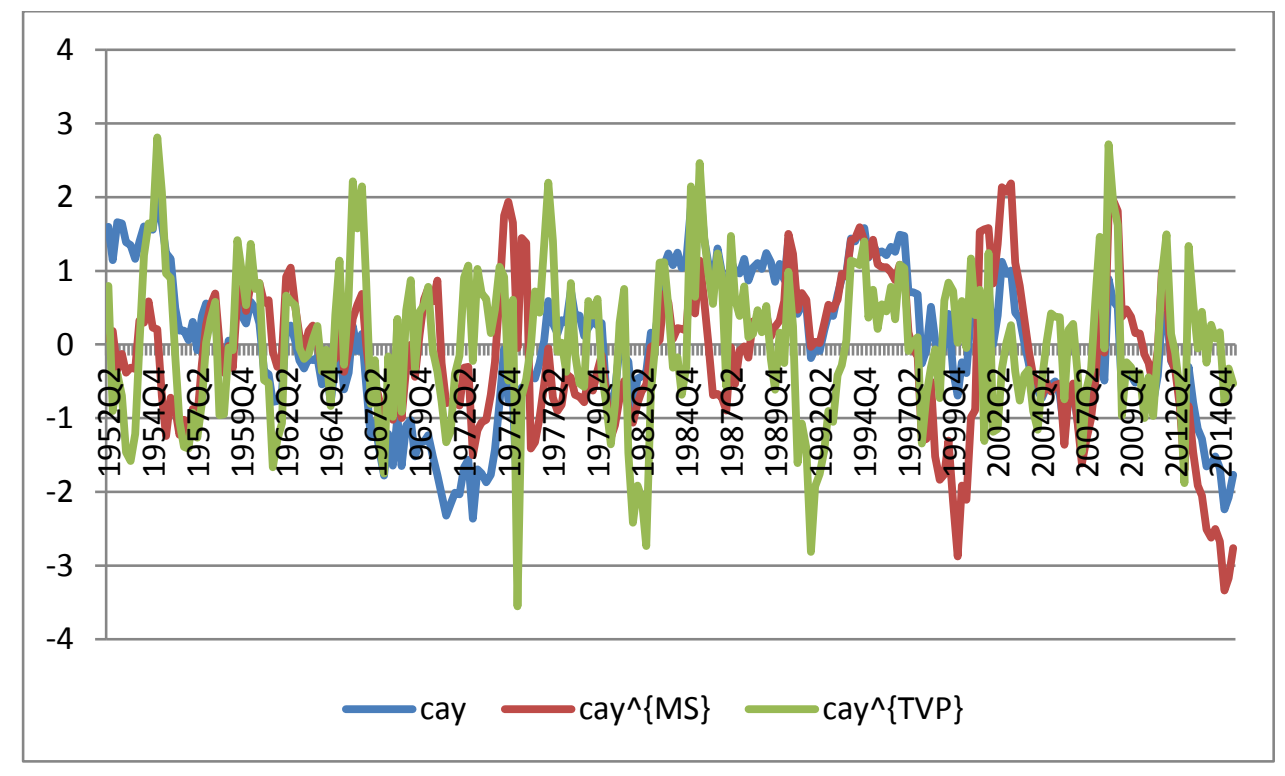

Note: $\operatorname{cay}^{\wedge}\{\mathrm{MS}\}$ and $\mathrm{cay}^{\wedge}\{\mathrm{TVP}\}$ stands for $c a y^{M S}$ and $c a y^{T V P}$ respectively.

\footnotetext{
${ }^{4}$ The estimated wealth and income elasticities, as tabulated in Table 1 of Bianchi et al., (2017), used to derive cay and cay ${ }^{M S}$ respectively are: $0.1246(0.0952,0.1540)$ and $0.7815(0.7486,0.8144)$, and $0.2679(0.2505$, $0.2852)$ and $0.6071(0.5873,0.6270)$, with the 95 percent confidence bands in parentheses.

${ }^{5}$ While the mean of cay is zero, that of $c a y^{M S}$ and $c a y^{T V P}$ are negative and positive respectively, with all the measures showing strong evidence of autocorrelation and heteroskedasticity. Complete details of these results are available upon request from the authors.
} 
Next, we turn to the causality-in-quantiles test that we use to evaluate the performance of the three measures of the consumption-wealth ratios with regard to predicting excess return and volatility. ${ }^{6}$ Figures 3 and 4 display the results from the causality-in-quantiles test for excess stock returns (exsr) and volatility (exsv). We find that cay, cay ${ }^{M S}$, and $c a y^{T V P}$ predict exsr, in general, over its entire conditional distribution, with the exception of the quantile 0.10 of exsr, which cannot be predicted by $c a y^{M S}$, and 0.90 , which cannot be explained by both cay and $c a y^{T V P}$. It is important to note (and in contrast to the results reported by Bianchi et al. 2016 based on a misspecified linear predictive regression model, Bekiros and Gupta, 2015), it is not necessarily true that $c a y^{M S}$ is always the stronger predictor (in terms of significance) of exsr when compared to cay, which in turn, corroborates the findings of Balcilar et al. (2017a). If we look at the results closely, we observe that $c a y^{T V P}$ is the strongest predictor of exsr over the quantile range of 0.10 to 0.30 , while cay does best at quantiles $0.50-0.60,0.70$ 0.75 and 0.85 , and $c a y^{M S}$ having the strongest causal influence (in terms of significance) over the remaining quantiles, i.e., $0.35-0.45,0.65,0.80$ and $0.90 .{ }^{7}$ However, we find that cay,

\footnotetext{
${ }^{6}$ We also conducted standard linear Granger causality tests involving the three alternative measures of the consumption-aggregate wealth ratios. As in Bianchi et al. (2016) and Balcilar et al. (2017a), the linear model confirmed that cay ${ }^{M S}$ is a stronger predictor $\left(\chi^{2}(1)=9.0214, p\right.$-value $\left.=0.0027\right)$ than cay $\left(\chi^{2}(1)=8.4507, p\right.$ value $=0.0036)$ for $e x s r$, however, there was no evidence of predictability with regard to $\operatorname{cay}^{T V P}\left(\chi^{2}(1)=0.5428, p\right.$ value $=0.4613)$. But, as in Balcilar et al. (2017a), the Brock et al. (1996, BDS) test of nonlinearity and the Bai and Perron (2003) tests of multiple structural breaks indicated that the linear models with three measures of consumption-aggregate wealth ratios (considered in turn) are misspecified, and hence, results from the standard Granger tests for noncausality cannot be relied upon. In other words, we need to base our inference on a nonparametric approach, which is robust to such misspecifications, and in the process provides us with a strong motivation to use the $k$-th order causality-in-quantiles test. When we conducted the BDS test on the errors for the equity premium equation and the volatility equation, we could not reject the null hypothesis of iid residuals for the various quantiles $(0.10,0.20, \ldots, 0.90)$ considered, suggesting that there is no remaining nonlinearity between the equity premium and its volatility with the three predictors considered in turn. In other words, the nonparametric framework of ours is not misspecified. Complete details of tests for linear Granger noncausality, nonlinearity, and multiple structural breaks are available upon request from the authors.

${ }^{7}$ As an anonymous referee pointed out, our analysis is silent on whether the gains in predictability across the three alternative measures of the consumption-wealth ratio over the various quantiles of the conditional distribution are statistically significant. This is indeed correct. However, we follow the extant literature of insample predictability (see Rapach and Zhou, 2013), as well as Bianchi et al., (2017), in drawing the conclusions based on the strength of the test statistic, after the predictors have been standardized. In order to assess statistical significance, we would need in-sample predicted values of exsr, and then we could apply standard forecast comparison tests (like Diebold and Mariano, 1995), which in turn, requires parameter estimates of the nonparametric causality-in-quantiles framework. However, in a nonparametric framework, this is not straightforward. To do so, we would need to employ the first-order partial derivative. Estimation of the partial derivatives for nonparametric models can experience complications because nonparametric methods exhibit slow convergence rates, which can depend on the dimensionality and smoothness of the underlying conditionalexpectation function. One could look at a statistic that summarizes the overall effect or the global curvature (i.e., the global sign and magnitude), but not the entire derivative curve. In this regard, a natural measure of the global curvature is the average derivative (AD). One could use the conditional pivotal quantile, based on approximation or the coupling approach of Belloni et al., (2017), to estimate the partial ADs. The pivotal coupling approach additionally can approximate the distribution of AD using Monte Carlo simulation. We leave this for future research and follow, at this stage, the extant literature on in-sample predictability comparisons across alternate predictors based on the strength of the causality statistic. Although one should not expect to have a one-to-one correspondence between our nonparametric causality-in-quantiles model and a standard
} 
$c a y^{M S}$, and $c a y^{T V P}$ fail to predict exsv over its entire conditional distribution - a result in line with the work of Balcilar et al. (2017a), but unlike that of Ludvigson and $\mathrm{Ng}$ (2007), with the result from the latter study being unreliable due to the possibility of misspecification of the linear model (Bekiros and Gupta, 2015).

In sum, the predictive ability of the three measures of the consumption-wealth ratio for exsr is contingent on the state of the stock market. In general, cay $^{T V P}$ is the most important of the three measures during a bear market, and cay performs strongly around the median to the moderately higher quantiles, i.e., when the market is performing in normal to good phases. The third measure, $c a y^{M S}$, in turn, tends to do well during a bull market, and for moderately poor phases. Hence, an investor who wants to predict stock returns to carry out portfolio allocation needs to rely on all three measures of the consumption-wealth ratio, as each of them individually caries valuable information about future stock returns at various phases of the stock market. In other words, an investor cannot rely all the time on a single measure of the consumption-wealth ratio to make his or her portfolio-allocation decision, but rather needs to condition his or her choice of the appropriate consumption-wealth ratio on and estimate of the state of the equity market. ${ }^{8,9}$ Note that, individually though each of the measures tend to have their strongest predictability around the median (below or above) of the conditional distribution, which corresponds to when the market functions in its normal mode, resulting in the hump-shaped nature of the test statistic. This could be an indication of agents in the equity market herding when the market is either in its bear and bull phases (Balcilar et al., 2016d), while when the market is performing normally, investors look to

quantile-regression approach, applying the Diebold and Mariano (1995) test to the in-sample predictions recovered across the various quantiles indicated that in the majority of cases predictability is statistically different between $c a y, c a y^{M S}$ and $c a y^{T V P}$. Complete details of these results are available upon request from the authors.

${ }^{8}$ Based on the suggestion of an anonymous referee we also estimated a GARCH model (specifically the GJRGARCH, Glosten et al., 1993, model to capture leverage) and also conducted the the Nishiyama et al., (2011) test. Under the GARCH framework, we observed that cay $^{T V P}$ failed to predict excess returns and volatility, while predictability was again restricted to returns only with $c a y$ and $c a y^{M S}$, with the latter being a stronger predictor. These results are in line with our linear Granger tests (discussed in Footnote 6). When we used the Nishiyama et al., (2011) test, cay, cay ${ }^{M S}$ and $c a y^{T V P}$ all predicted excess returns, but not volatility, with cay ${ }^{T V P}$ being the strongest predictor followed by cay and then $c a y^{M S}$. Given that our quantiles-based results are more informative than these conditional-mean based models (because we study the entire conditional distribution), and because our results does not suffer from misspecification involving linearity, we do not present these results formally, but make them available upon request. However, with the Nishiyama et al., (2011) test being the predecessor to our test, we report these results in Table $\mathrm{A} 2$ at the end of the paper.

${ }^{9}$ While, it is true that the alternative consumption-wealth ratios tend to carry more accurate information for predicting excess stock returns relative to its competitors conditional on the state of the market, i.e., at specific points of the conditional distribution, on average over the quantiles, the test statistic under cay tends to have the highes value of 3.3277 . 
obtain information from predictors (in our case the various consumption-wealth ratios) to try and make their portfolio holdings more profitable.

Figure 3. Causality-in-quantiles of Excess stock returns (exsr)

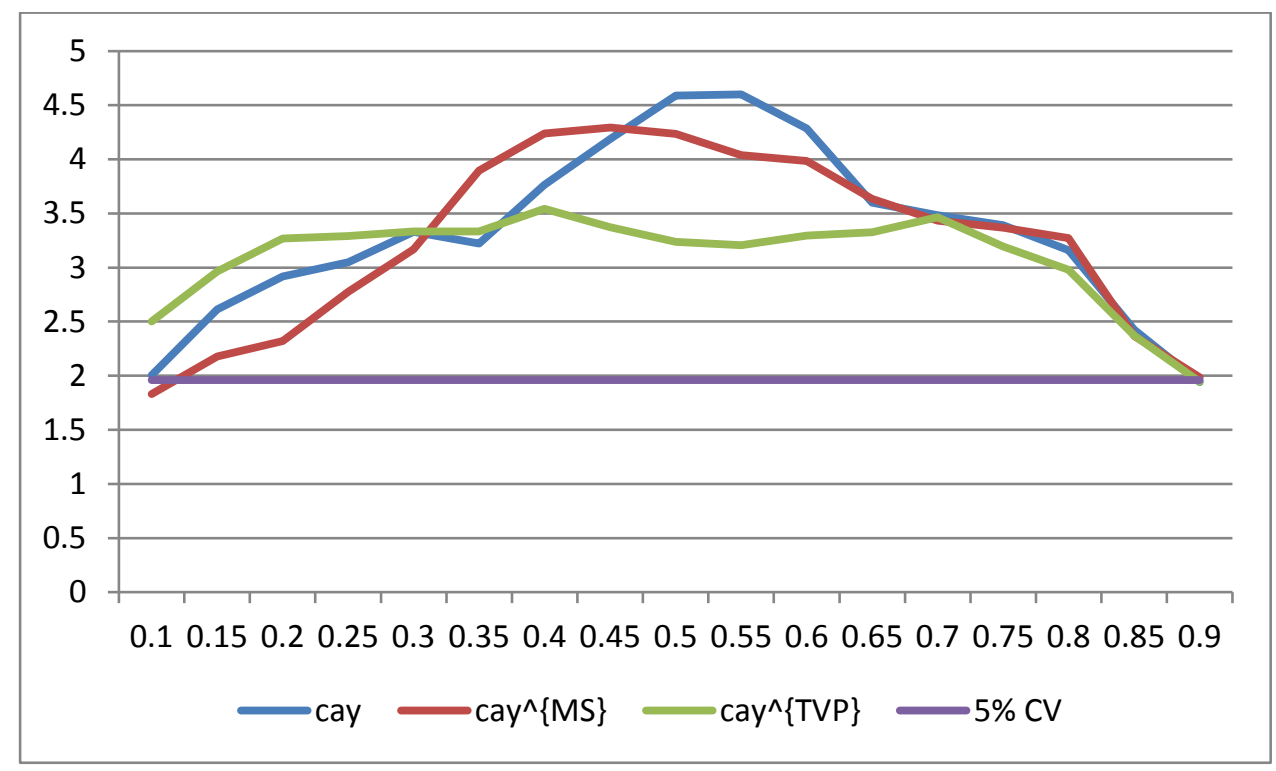

Note: See Notes to Figure 2; the horizontal axis depicts the various quantiles and the vertical axis measures the test statistic.

Figure 4. Causality-in-quantiles of excess stock returns volatility (exsv)

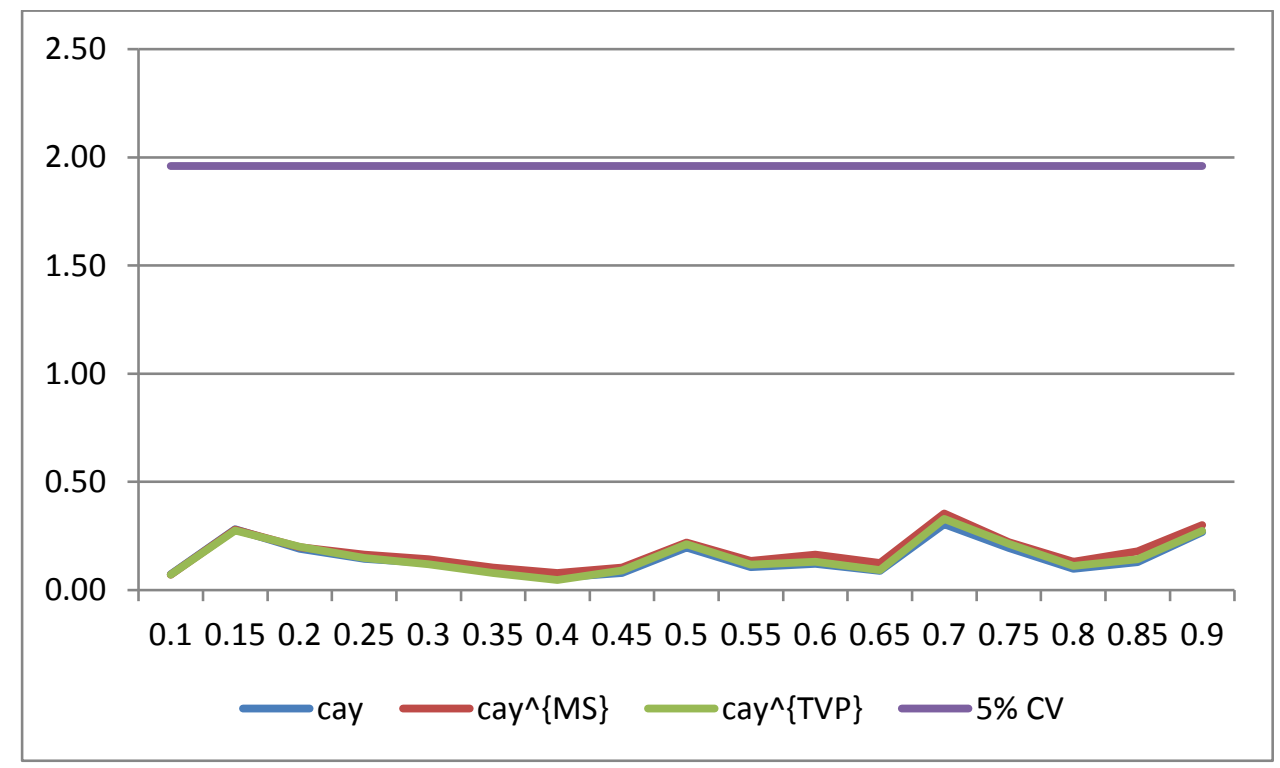

Note: See Notes to Figure 3. 


\section{Conclusion}

We have contributed to this literature on the consumption-aggregate wealth ratio (cay) and the predictability of equity-market fluctuations initiated by Lettau and Ludvigson (2001), in that (a) we have developed a time-varying measure of cay (cay ${ }^{T V P}$ ) using time-varying cointegration techniques, (b) we have compared the predictive ability of the $c a y^{T V P}$ measure with the predictive ability of the cay and the Markov-switching cay (cay ${ }^{M S}$ introduced by Bianchi et al. 2016) measures with regard to excess stock returns and volatility in the US over the period 1952:Q2-2015:Q3, and, (c) we have analyzed the predictive ability of the three measures of the consumption-aggregate wealth ratio using a nonparametric causality-inquantiles test developed by Balcilar et al. (2016a). This test renders it possible to analyze higher-order predictability over the entire conditional distributions of returns and volatility and, being a nonparametric test, it controls for the widely-reported misspecification associated with linear predictive models of stock-markets returns.

We find that cointegration exists, in a time varying fashion, between consumption, asset wealth, and labor income. In addition, while there is no evidence of predictability for excess returns volatility from any of the three measures of the consumption-aggregate wealth ratios, they tend to act as strong predictors (in terms of significance) of stock returns, with each of the ratios being important at certain phases of the equity market. In general, cay $^{T V P}$ is important during a bear market, cay performs strongly when the market is performing in the normal to good phases, and $c a y^{M S}$, in turn, tends to do well during a bull market and for moderately poor phases. Hence, investors can obtain important information from all three measures, contingent on the state the stock market is in.

As part of future research, it would be interesting to extend our study in order to examine whether our results regarding the predictive value of the three measures of the consumptionaggregate wealth ratio continue to hold in an out-of-sample forecasting exercise because there is not necessarily a one-to-one coorespondence between in-sample and out-of-sample predictabilityy (Rapach and Zhou, 2013; Bonaccolto et al. forthcoming). One of the limitations of our in-sample predictability analysis, as is the case with any other Granger tests for noncausality, is that, while we can discuss whether a variable has predictive content for the dependent variable, we are not able to measure the extent of (statistical and economic) gains derived from using the predictor in question. An out-of-sample exercise would allow this issue to be addressed as we would be able to compare by how much the forecast error 
and economic utility produced from the model are better or worse than those obtained from a benchmark model (i.e., the model without the predictor). ${ }^{10}$

\section{References}

Afonso, A., Sousa, R.M., 2011. Consumption, wealth, stock and government bond returns: international evidence. The Manchester School, 79(6), 1294-1232.

Bai, J., Perron, P., 2003. Computation and analysis of multiple structural change models. Journal of Applied Econometrics, 18, 1-22.

Balcilar, M., Bekiros, S., Gupta, R., 2016a. The role of news-based uncertainty indices in predicting oil markets: a hybrid nonparametric quantile causality method. Empirical Economics, doi: 10.1007/s00181-016-1150-0.

Balcilar, M., Gupta, R., Pierdzioch, C. 2016b. Does Uncertainty Move the Gold Price? New Evidence from a Nonparametric Causality-in-Quantiles Test. Resources Policy, 49(1), 7480.

Balcilar, M., Gupta, R., Pierdzioch, C., and Wohar, M.E. 2016d. Terror Attacks and StockMarket Fluctuations: Evidence Based on a Nonparametric Causality-in-Quantiles Test for the G7 Countries. European Journal of Finance, http://dx.doi.org/10.1080/1351847X.2016.1239586.

Balcilar, M., Gupta, R., Sousa, R.M., and Wohar, M.E. 2017a. The predictability of cay and $c a y^{M S}$ for stock and housing returns: A nonparametric causality in quantile test. International Review of Economics and Finance, 48(1), 269-279.

Balcilar, M., Gupta, R., Pierdzioch, C., and Wohar, M.E. 2017b. Do Terror Attacks Affect the Dollar-Pound Exchange Rate? A Nonparametric Causality-in-Quantiles Analysis. North American Journal of Economics and Finance, 41(1), 44-56.

Balcilar, M., Gupta, R., Pierdzioch, C. 2017c. On Exchange-Rate Movements and Gold-Price Fluctuations: Evidence for Gold-Producing Countries from a Nonparametric Causality-inQuantiles Test. International Economics and Economic Policy, 14(4),691-700.

Bekiros, S., Gupta, R., 2015. Predicting stock returns and volatility using consumptionaggregate wealth ratios: a nonlinear approach. Economics Letters, 131, 83-85.

\footnotetext{
${ }^{10}$ Because the out-of-sample forecasting model of the causality-in-quantiles test is still under development, we could only obtain preliminary results, which in turn suggested that the model with cay ${ }^{T V P}$ tends to perform the best (especially at lower quantiles) in forecasting exsr, with it producing gains in terms of the mean squared forecast errors ranging from $8 \%$ to $1 \%$ relative to the benchmark. The model with cay (especially around the median) follows next with gains ranging from $5 \%$ to $1 \%$. Complete details of these results are available upon request from the authors.
} 
Belloni, A., Chernozhukov, V., Chetverikov, D., Fernandez-Val, I. 2017. Conditional quantile processes based on series or many regressors. ArXiv e-prints: https://arxiv.org/abs/1105.6154.

Bianchi, F., Lettau, M., Ludvigson, S.C., 2017. Monetary policy and asset valuation. National Bureau of Economic Research Working Paper No. 22572.

Bonaccolto, G., Caporin, M., Gupta, R., Forthcoming. The dynamic impact of uncertainty in causing and forecasting the distribution of oil returns and risk. Physica A: Statistical Mechanics and its Applications.

Brock, W., Dechert, D., Scheinkman, J., and LeBaron, B. (1996). A test for independence based on the correlation dimension. Econometric Reviews, 15 197-235.

Caporale, G.M., Sousa, R.M., 2016. Consumption, wealth, stock and housing returns: Evidence from emerging markets. Research in International Business and Finance, 36, $562-578$.

Dickey, D., and Fuller, W., (1981). Likelihood ratio statistics for autoregressive time series with a unit root. Econometrica, 49, 1057-1072.

Diebold, F.X. and Mariano, R.S. (1995), Comparing Predictive Accuracy. Journal of Business and Economic Statistics, 13, 253-263.

Glosten, L.R., Jagannathan, R., and Runkle, D.E., 1993. On the relation between the expected value and volatility of the nomial excess return on stocks. Journal of Finance, 48, 17791801.

Jeong, K., Härdle, W.K., Song, S., 2012. A consistent nonparametric test for causality in quantile. Econometric Theory, 28(4), 861-887.

Kapetanios, G., Shin, Y. and Snell, A. (2003). Testing for a unit root in the nonlinear STAR framework. Journal of Econometrics, 112, 359-379.

Lettau, M., Ludvigson, S., 2001. Consumption, aggregate wealth, and expected stock returns. Journal of Finance, 41(3), 815-849.

Lettau, M., Ludvigson, S., 2004. Understanding trend and cycle in asset values: Reevaluating the wealth effect on consumption. American Economic Review, 94, 276-299.

Ludvigson, S. C. and $\mathrm{Ng}$, S. 2007. The empirical risk-return relation: a factor analysis approach. Journal of Financial Economics, 83, 171-222.

Ludwig A., and Sløk, T., 2004. The Relationship between Stock Prices, House Prices and Consumption in OECD Countries. The B.E. Journal of Macroeconomics, 4(1), 1-28. 
Nishiyama, Y., Hitomi, K., Kawasaki, Y., Jeong, K., 2011. A consistent nonparametric test for nonlinear causality - Specification in time series regression. Journal of Econometrics, $165,112-127$.

Phillips, P., and Perron, P., 1988. Testing for a unit root in time series regression. Biometrika, $75,335-346$.

Rapach, D., Zhou, G., 2013. Forecasting stock returns. In: Elliott, G., Timmermann, A., Eds. Handbook of Economic Forecasting, 328-383, Amsterdam: Elsevier.

Rocha Armada, M.J., Sousa, R.M., Wohar, M.E., 2015. Consumption growth, preference for smoothing, changes in expectations and risk premium. Quarterly Review of Economics and Finance, 56, 80-97.

Simo-Kengne, B., Miller, S., Gupta, R., and Aye, G., 2015. Time-Varying Effects of Housing and Stock Returns on U.S. Consumption. The Journal of Real Estate Finance and Economics, 50 (3), 339-354.

Sousa, R.M., 2010. Consumption, (dis)aggregate wealth, and asset returns. Journal of Empirical Finance, 17(4), 606-622.

Sousa, R.M., 2015. Linking wealth and labour income with stock returns and government bond yields. European Journal of Finance, 21(10/11), 806-825. 


\section{APPENDIX:}

Table A1. Unit Root Tests

Panel (a): Data in Levels

\begin{tabular}{|c|c|c|c|c|c|c|}
\hline & \multicolumn{2}{|c|}{ ADF } & \multicolumn{2}{c|}{ PP } & \multicolumn{2}{c|}{ KSS } \\
\hline Variable & Constant & $\begin{array}{c}\text { Constant }+ \\
\text { Trend }\end{array}$ & Constant & $\begin{array}{c}\text { Constant }+ \\
\text { Trend }\end{array}$ & Constant & $\begin{array}{c}\text { Constant }+ \\
\text { Trend }\end{array}$ \\
\hline $\mathrm{c}$ & -1.273 & -1.789 & -1.450 & -1.291 & -1.287 & -1.948 \\
\hline $\mathrm{a}$ & -0.062 & -2.846 & -0.195 & -3.099 & -0.165 & -3.452 \\
\hline $\mathrm{y}$ & -2.026 & -1.110 & -1.922 & -1.225 & -1.792 & -1.482 \\
\hline
\end{tabular}

Panel (b): Data in First-Differences

\begin{tabular}{|c|c|c|c|c|c|c|}
\hline & \multicolumn{2}{|c|}{ ADF } & \multicolumn{2}{c|}{ PP } & \multicolumn{2}{c|}{ KSS } \\
\hline Variable & Constant & $\begin{array}{c}\text { Constant }+ \\
\text { Trend }\end{array}$ & Constant & $\begin{array}{c}\text { Constant }+ \\
\text { Trend }\end{array}$ & Constant & $\begin{array}{c}\text { Constant }+ \\
\text { Trend }\end{array}$ \\
\hline $\mathrm{c}$ & $-6.560 * * *$ & $-7.664 * * *$ & $-11.830 * * *$ & $-11.893 * * *$ & $-5.215 * * *$ & $-6.169 * * *$ \\
\hline $\mathrm{a}$ & $-12.626 * * *$ & $-12.609 * * *$ & $-12.929 * * *$ & $-12.913 * * *$ & $-8.001 * * *$ & $-7.987 * * *$ \\
\hline $\mathrm{y}$ & $-15.571 * * *$ & $-15.764 * * *$ & $-15.637 * * *$ & $-15.806 * * *$ & $-11.929 * * *$ & $-12.040 * * *$ \\
\hline
\end{tabular}

Note: $* * *$ indicates rejection of the null hypothesis of a unit root at $1 \%$ level of significance.

Table A2: Nishiyama et al., (2011) Test Results

\begin{tabular}{|c|c|c|c|}
\hline Dependent variable & Independent variable & Mean (Returns) & Volatility (Variance) \\
\hline \multirow{3}{*}{ Exr } & $c a y$ & $16.282^{* *}$ & 5.978 \\
\cline { 2 - 4 } & $c a y^{M S}$ & $15.932 * *$ & 8.798 \\
\cline { 2 - 4 } & $c a y^{T V P}$ & $22.430 * *$ & 5.861 \\
\hline
\end{tabular}

Note: $* *$ indicates rejection of the null hypothesis of non-Granger causality of returns (volatility) at the 5\% critical value of 14.38 . 